\title{
Applications of biomass and recycled fibers in construction engineering: an overview
}

\begin{abstract}
Today' indiscriminate infrastructural growth is leading towards rapid environmental degradation. Steel, cement, synthetic polymers and metal alloys used for construction activities are energy intensive as well as can cause environmental pollution during their entire life cycle. We have enough natural as well as recycled resources and research should be carried on these natural and recycled resources. Development of natural and recycled fiber composite has started to begin recently. Sustainable design like fiber reinforced concrete has a low impact on the environment. Use of "green" and recycled materials embodies such as natural and recycled fibers offers low energy costs. Their use must have high durability and low maintenance leading to sustainable construction materials; Environmental issues are playing an important role in the sustainable development of the cement and concrete industry. This paper reviews some of the work on concrete reinforcement using non textile value and recycled fibers made up of biomass, carpet waste, plastic bottles and other industrial and domestic waste . This paper also provides a summary of the properties and applications.
\end{abstract}

Volume I Issue 5 - 2017

VD Gotmare, Kole S S

Department of Textile Manufactures, VJTI Matunga, India

Correspondence: Kole S S, Department of Textile Manufactures, VJTI Matunga, Mumbai-19, India, Tel 9021790179, Email sushant.kole1996@gmail.com

Received: January 24, 2017 | Published: May 05, 2017

Keywords: biomass fiber, recycled fibers. applications of FRC

Abbreviations: FRC, fiber reinforced concrete; SBR, styrene-butadiene latex rubber; HPFRC, high-performance fiber-reinforced composites; UHPFRC, ultra-high-performance fiber-reinforced concretes; OPC, ordinary portland cement; PC, plain concrete; CC-FRC, coconut coir fiber reinforced concrete; S-FRC, steel fiber reinforced concrete.

\section{Introduction}

Concrete is the most frequently used construction material in the world. However, it has low tensile strength, low ductility, and low energy absorption. An intrinsic cause of the poor tensile behavior of concrete is its low toughness and the presence of defects. Therefore improving concrete toughness and reducing the size and amount of defects in concrete would lead to better concrete performance. An effective way to improve the toughness of concrete is by adding a small fraction (usually $0.5-2 \%$ by volume) of short fibers to the concrete mix during mixing. In the fracture process of fiber reinforced concrete (FRC), fibers bridging the cracks in the matrix can provide resistance to crack propagation and crack opening before being pulled out or stressed to rupture. After extensive studies it is widely reported that such fiber reinforcement can significantly improve the tensile properties of concrete. Orders of magnitude increases in toughness (energy absorption) over plain concrete are commonly observed ${ }^{1}$

Natural fibers are prospective reinforcing materials and their use until now has been more traditional than technical. They have long served many useful purposes but the application of materials technology for the utilization of natural fibers as the reinforcement in concrete has only taken place in comparatively recent years. The distinctive properties of natural fiber reinforced concretes are improved tensile and bending strength, greater ductility, and greater resistance to cracking and hence improved impact strength and toughness. Besides its ability to sustain loads, natural fiber reinforced concrete is also required to be durable. Durability relates to its resistance to deterioration resulting from external causes as well as internal causes ${ }^{2}$ also the recycled material like plastic, carpets, tiers and automotive goods which is almost thrown on the land fields can be effectively used in the various civil engineering applications. Significant effort has been devoted to the reduction, reuse, and recycling of the waste materials. Typically, recycling technologies are divided into primary, secondary, tertiary, and quaternary approaches. Primary approaches involve recycling a product into its original form. Secondary recycling involves processing a used product into a new type of product that has a different level of physical and/or chemical properties. Tertiary recycling involves processes, such as pyrolysis and hydrolysis, which convert the waste into basic chemicals or fuels. Quaternary recycling refers to waste-to-energy conversion through incineration. All four approaches exist for textile, plastic, and paper recycling. Studies have indicated that many forms of fibers recovered from various waste streams are suitable for concrete reinforcement. The advantages of using such recycled fibers include generally lower cost to process than virgin fibers, and the elimination of the need for waste disposal in landfills.

\section{Overview of various recycled fibers}

Recycled fibers from carpet waste: The carpet waste generated each year and accumulated in landfills represents an abundance of useful resources, as this waste may be converted into various useful products. $^{4}$

The amount of carpet waste, including production waste and postconsumer carpet, is estimated at over 2,000,000 tons/year. Because of the high cost of developing and managing landfills, waste disposal in landfills has become increasingly difficult. A carpet typically consists of two layers of backing (usually fabrics from polypropylene tape yarns), joined by $\mathrm{CaCO}_{3}$-filled styrene-butadiene latex rubber (SBR), and face fibers (the majority being nylon 6 and nylon 66 textured yarns) tufted into the primary backing, as illustrated in Figure 1. The SBR adhesive is a thermo set material, which cannot be remolded or reshaped. Some waste is generated before the application of SBR. Such waste is termed "soft waste," and most is reused as filling material or nonwoven mats. The waste containing the SBR (termed "hard 
waste") has not been found to have significant uses and forms the major part of the waste going into the landfills. The fibers in most carpet waste are nylon face fibers and polypropylene tape yarns, both proven durable and effective in FRC. Therefore, it is logical to expect beneficial effects from recycled carpet waste fibers in concrete shown in Figure 2. ${ }^{4}$

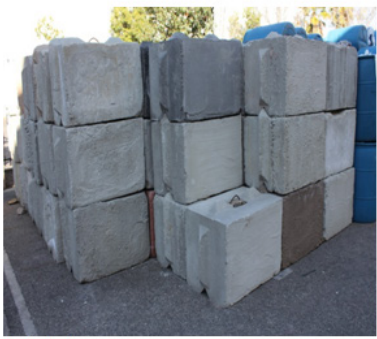

(A)

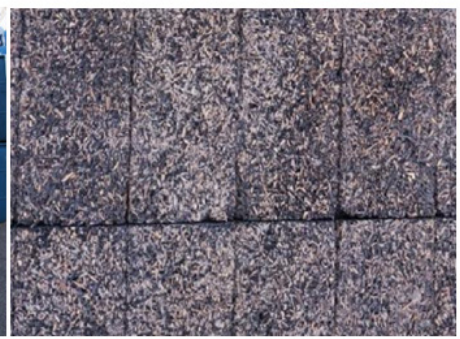

(B)

Figure I (A) Ordinary Concrete blocks, (B) Concrete blocks made up of cellulosic waste.

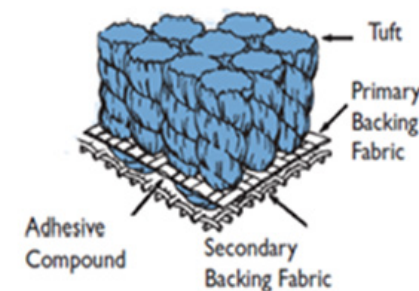

Backing Fabric

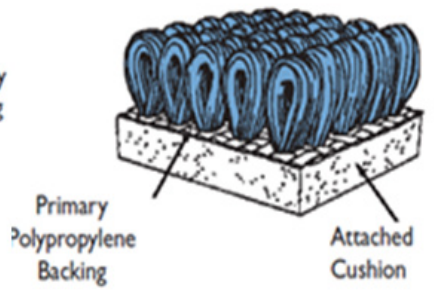

Figure 2 Waste Carpet Structure.

Recycled fiber from plastic bottles: Waste generated from pre-and-post consumer waste is becoming a concerning issue both with the manufacturers and the disposal authorities. Concrete with recycled short fibers shows positive contribution to utilize the waste resources and helps to protect the environment from containment. Also it is a provision of an alternative material for the construction industry shown in Figure $3 .^{5-7}$ Waste PET bottles and other plastic base material had been reworked for drinking and other bottles by melting fusion, which turned out to be too costly. Therefore waste PET bottles will be insured to recycle to make short fibers to reduce the rework cost. Certain quantity of recycled fibers can be beneficial for enhancing the properties of plain concrete. But it is not necessary that all properties will be improved, the addition of fibers may increase certain properties and at the same time may decrease other ones. Therefore the fibers in appropriate quantity should be selected. To investigate the effects of fiber quantity on mechanical properties of recycled short fiber reinforced concrete and identifies the suitable materials to enhance the mechanical properties of concrete in Figure 4.

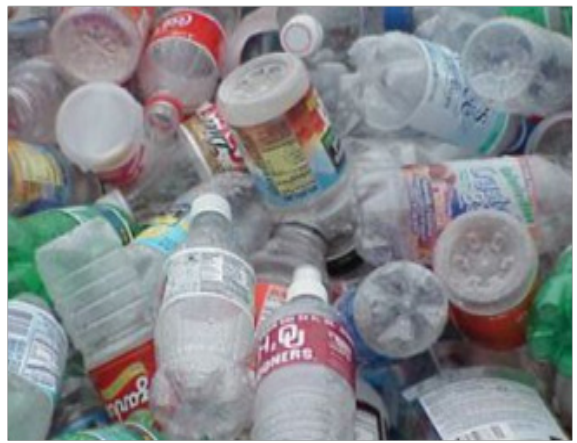

Figure 3 Waste drinking bootless

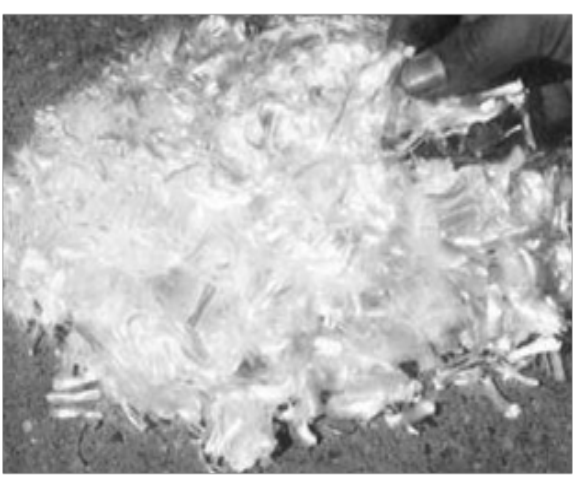

Figure 4 Recycled staple PET fibers.

Biomass fiber in construction area: Natural fibers reinforced with polymer concrete base composites have gained more interest because of they are less expensive, light weight, easy processing, high specific modulus and also sustainable. The interest in long term sustainability of material resources has make advancements in bio-composites or polymer concrete materials made up with natural fibers and resin. Polymeric composites may be understood as the combination of two or more materials, for example, reinforcement elements or filler involved by a polymeric matrix.

Natural fibers such as jute, sisal, pineapple, abaca and coir have been studied as reinforcement and filler in cement based composites. Besides, Plant fibers from agricultural crops are renewable materials which have potential for creating green products and replacing synthetic materials. ${ }^{1}$ Amongst the all the natural fibers listed, Bagasse is biomass remaining after sugarcane stalks are crushed to extract their juice in Figure 5. A sugar factory produces nearly $30 \%$ of Bagasse out of total crushing. Many research efforts till date were attempted to use Bagasse as a renewable feedstock as domestic fuel for power generation and for the production of bio-based material. The use of Bagasse as fuel will produce significant amount of carbon during its use, which is not desirable. However, the consumption of the Bagasse is very low, especially in Asian country ${ }^{9}$ Transforming Bagasse into high-quality panel products provides a prospective solution the Bagasse-fiber-based cementinious composite has a potential as the core material replacing high density and expensive wood-based fiberboard shown in Figure 6. Bagasse is also commonly used for various building boards whose acoustical properties make them very desirable for homes, offices, and other buildings. ${ }^{10,11}$

a. Capability, improved capacity against delamination, spalling and fatigue.

b. High volume fraction $(<2 \%)$ : The fibers used at this level lead to strain hardening of the composites. Because of this improved behavior, these composites are often referred as High-performance fiber-reinforced composites (HPFRC).In the last decade; even better Composites were developed and are referred as ultra-high-performance fiber-reinforced concretes (UHPFRC).

\section{Overview of case study on bio-mass fiber in construc- tion area}

The studies reported by Sivarajan and Kanadaswami 2007, 2008, $2009^{12}$ on the workability, mechanical and flexural properties of fibrous concrete with the same natural fibers shows that The optimum volume fraction and aspect ratio obtained from the earlier studies are $1 \cdot 5 \%$ and 60 . Hence, in the present study, the fibrous such as coir 
and sugarcane were mixed in the concrete with a volume fraction of $1 \cdot 5 \%$ and aspect ratio of 60 were selected. Cube specimens of 150 $\mathrm{mm}$ size for compressive strength, cylinder specimens of $150 \mathrm{~mm}$ diameter $\times 300 \mathrm{~mm}$ height and prisms of size of $500 \times 100 \times 100 \mathrm{~mm}$ were casted to study the mechanical strength properties. The test programme also consists of fabricating reinforced concrete beams of length, $2 \mathrm{~m}$ having identical cross-section of $100 \times 150 \mathrm{~mm} \cdot{ }^{13,14}$



Figure 5 Sugarcane fibers.

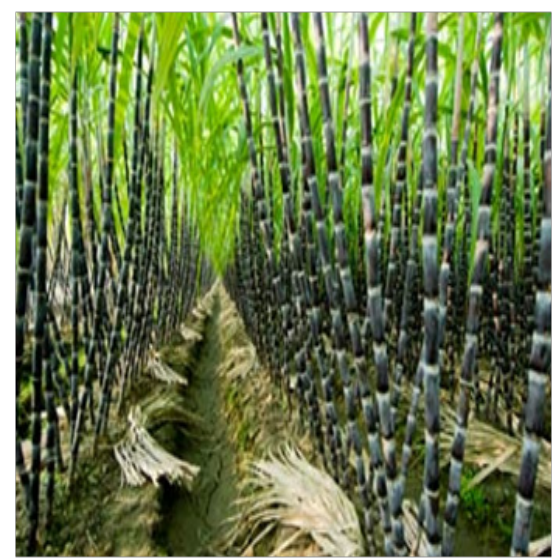

Figure 6 Sugarcane plantation.

To avoid balling effect of fibers, first aggregates and cement were put and allowed to get mixed for 1 min and water was added within $2 \mathrm{~min}$. Then fibers were uniformly dispersed throughout the mass with slow increment. Now concrete was allowed to mix for $3 \mathrm{~min}$. All the specimens were well compacted using table vibrator. The specimens were demolded after 1 day and then placed in a curing tank with $90 \%$ relative humidity and $23^{\circ} \mathrm{C}$ for 28 days of curing. For 12 hours prior to the testing, the specimens were allowed to air dry in the laboratory. After that all the samples were tested for mechanical and durability properties where they found excellent performance with respect to compressive, flexural, sulphur and frizzing and thawing effect than ordinary cement concrete material.

\section{Overview of case study on recycled fiber in construc- tion area}

Field study using carpet waste fiber in construction: Shaw Industries, Inc., in 1994, completed an $11,000 \mathrm{~m}^{2} \mathrm{R} \& \mathrm{D}$ Center in Dalton, which used concrete reinforced with carpet waste fibers in the construction project. About 20 tons of carpet production waste was consumed in the project, which would otherwise have been sent to a landfill.
The concrete mix followed a typical design for concrete with a 28 MPa (4,000 psi) compressive strength, consisting of cement, sand, and rock. The water-cement ratio was 0.5 and the cement content was about $260 \mathrm{~kg} / \mathrm{m}^{3}$. Super plasticizer was added to maintain the desired workability. ${ }^{15-19}$ The amount of waste fiber included was $5.95 \mathrm{~kg} / \mathrm{m}^{3}$. Mixing was done by adding fibers to the mixing truck directly, after which the fibers were found to be uniformly dispersed in the concrete without balling or clumping. Mixing, pouring, and finishing followed standard procedures, used conventional equipment, and went smoothly. The compressive and flexural strengths exceeded specifications, and reduced shrinkage cracking was observed. Such concrete containing waste fibers was used for floor slabs, driveways, and walls of the building. The project demonstrated the feasibility of using large amounts of carpet waste for concrete reinforcement in a full-scale construction project. Besides reducing the need for land filling, the use of low-cost waste fiber for concrete reinforcement could lead to improved infrastructure with better durability and reliability.

Experimental study using recycled polyester and coir fiber in construction: Sandaruwini A.H and W.E, Bandera K.A.J.M (1984) they studied the effect of recycled polyester and coir fiber together on the structural changes in the concrete material in this experiments they have used Ordinary Portland Cement (OPC), fine aggregate, coarse aggregate (maximum size of aggregate- $20 \mathrm{~mm}$ ), water to cement ratio of 0.62 , coconut coir fiber, steel fiber and PET fiber were used for preparation of plain concrete and fiber reinforced concrete samples. Mixture properties of used recycled short fibers, coconut coir fiber, steel fiber and PET fibers were used for preparation of fiber reinforced concrete to investigate the mechanical properties of plain concrete (PC) and FRC with different volume fraction. In this study, volume fraction 1,3 and $6 \%$ on fine aggregate replaced with coconut coir fiber which is having equal length of $50 \mathrm{~mm}$ and that was used for coconut coir fiber reinforced concrete (CC-FRC). ${ }^{11}$

The volume fraction $0.25,0.5$ and $0.75 \%$ on fine aggregate replaced with the steel fiber which is having equal length of $60 \mathrm{mmand}-$ that was used for steel fiber reinforced concrete (S-FRC). The volume fraction 1,2 and $3 \%$ on fine aggregate replaced with PET fiber which is having equal length of $55 \mathrm{mmand}$ that was used for PET fiber reinforced concrete (PET-FRC). A concrete mixer of rotating pan type was used in preparing the concrete mixtures. Coarse aggregate and fine aggregate were fed in the mixer along with part of mixing water and the mixer was operated. After mixing aggregate, cement was put and mixed for several minutes. after that short fibers were gradually fed with the balance amount of water, and concrete block were casted of size $150 \times 150 \times 150 \mathrm{~mm}$ and cured for 7, 14, 28days. Finally sample were tested for their compression, flexural and tensile strength and they concluded that introducing recycled fibers in the given concrete mix will improve its durability, provided it is required to load the recycled fiber with more higher doses than virgin material.

\section{Advantages of recycled and biomass fibers in reinfor- ced concrete}

a. Natural and recycled fibers offer many benefits for reinforcement

i. Low cost and abundant

ii. Renewable

iii. Non-hazardous-replacement of asbestos

b. Concrete with recycled short fibers shows positive effect to utilize 
the waste resources and helps to maintain the environment clean. Also it is a provision as an alternative material for the construction industry. ${ }^{12}$

c. Polymeric and synthetic fibers alter the energy absorption properties of the composites significantly. Uniform fiber distribution at various size scales improves mechanical properties of composite. A small microfiber stabilize the micro cracks and increase the strength by reducing the porosity of the cement paste and helps to increases the strength. ${ }^{8}$

d. Other benefits of FRC include improved fatigue strength, wear resistance, and durability of concrete material.

e. Utilizing natural and recycled fibers will reduces the load on the land fields

f. It is the way to create wealth from waste.

\section{Areas of application of FRC materials}
A. Shingles
B. Roof tiles
C. Pipes
D. Prefabricated shapes
E. Panels
F. Curtain walls
G. Slabs on grade
H. Precast elements
I. Composite decks
J. Impact resisting structures ${ }^{13}$

\section{Conclusion}

The use of biomass and recycled fibers from industrial or postconsumer waste could offer additional advantages of waste reduction and resources conservation. Concrete with natural, and recycled material combine very good mechanical properties with ecological characteristics have opened up the possibility of using them in sustainable civil and architectural applications. Fibrous materials can contribute for creating sustainable buildings that save the energy, reduce environmental impact and provide a quality indoor environment for their occupants. The utility of such green material will bring more technological strategies and alternative visions of how to include fibers for constructing sustainable places and it provides the path towards sustainability in the construction engineering area.

\section{Acknowledgments}

None.

\section{Conflict of interest}

Author declares there is no conflict of interest in publishing the article.

\section{References}

1. ACI Committee 506. State-of-the-art report on fiber reinforced concrete. Concrete International. 1982;6(12):15-27.

2. Shivrajan M, Kanadaswami, N Velmani, et al. Study on durability of natural fiber concrete composites using mechanical strength and micro structural properties. Bull Mater Sci. 2009;33(6):719-129.

3. Youjijang Wang, Wu HC, Victor $\mathrm{CH}$. Concrete reinforcement with recycled fibers. J material in civil eng. 2000;12(4).

4. Gardner HC. Carpet recycling technique. Indian fiber J. 2000;10(4):36-49.

5. Jaeo Marciano, Laredo doe Resis. Effect of textile waste on mechanical properties of polymer concrete. Materials Research. 2009;(12):63-67.

6. Environmental Protection Agency. Report on Plastics. EPA, USA; 2003.

7. Foti D. Preliminary analysis of concrete reinforced with waste bottles PET fibers. Construction Building Materials. 2011.

8. Edger Garea-Hernadez, Angel licea-clavere. Improvement of the interfacial compatibility between sugarcane Bagasse fibers. Polymer composites. 2004;25(2):134-145.

9. Patura JM. Alternative uses of sugarcane and its byproducts. Agriculture and Consumer Protection. 2004.

10. Qinglin Wu. Particle board from sugarcane bagasse for value added applications. 2004.

11. Namat karnran M. C-255 Concrete technology. University of Washington, USA; 2007.

12. Sahaya Ruben J, Basker G. Experimental study of coir fiber as concrete reinforcement material in cement based composites. J Eng Res \& applications. 2014;4(1):128-131.

13. Raúl F, Rosado K, Guise C, et al. Fibrous based material in sustainable civil and architectural applications-a Review. International Conference on engineering. University of Beira, Portugal; 2011.

14. American Concrete Institute. Report on the Physical Properties and Durability of Fiber-Reinforced Concrete. ACI, USA; 2010. p. 1-15.

15. Akcaozoglu S, Atis C. Effect of Granulated Blast Furnace Slag and fly ash addition on the strength properties of lightweight mortars containing waste PET aggregates. Construction \& Building Materials. 2011;25(10).

16. C Van Dillewijn, Chronica Botanica, Stechert-Hafner, et al. Botany of Sugarcane. Mass, USA; 1952. p. 333.

17. Collier BJ, Collier JR, Agarwal P, et al. Extraction and evaluation of fibers from sugar cane. Text Res J. 1992;62(12):741-748.

18. Costa SM, Mazzola PG, Silva JCAR, et al. Use of sugarcane Straw as a source of cellulose for textile fiber production. Industrial Crops and Products. 2013;42:189-194.

19. Rocha GJM, Goncalves AR, Oliveira BR, et al. Steam explosion pretreatment reproduction and alkaline delignification reactions performed on a pilot scale with sugarcane Bagasse for bio ethanol production. Industrial Crops \& Product. 2012;35(1):274-279. 